Skin

Appendage

Disorders
Skin Appendage Disord 2017;3:175-178

DOI: 10.1159/000471855
Received: January 17, 2017

Accepted: March 20, 2017

Published online: April 29, 2017

\title{
A Case of Circumscribed Scalp Morphea with Perineural Lymphocytes on Pathology
}

\author{
David Saceda-Corralo ${ }^{a}$ Aron G. Nusbaum ${ }^{b}$ Paolo Romanelli ${ }^{b}$ Mariya Miteva ${ }^{b}$
}

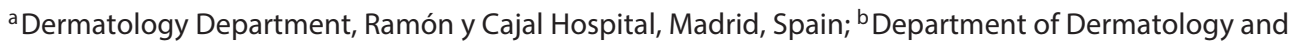

Cutaneous Surgery, University of Miami, Miami, FL, USA

\section{Established Facts}

- Round morphea involving the scalp is an uncommon clinical presentation, and biopsy in late stages may show slight changes.

\section{Novel Insights}

- Lymphocytic perineural infiltrate is a helpful histopathologic feature in the diagnosis of scalp morphea.

\section{Keywords}

Alopecia $\cdot$ Lymphocytic perineural infiltrate $\cdot$ Scleroderma .

Morphea $\cdot$ Coup de sabre $\cdot$ Scalp morphea $\cdot$ Cicatricial

alopecia

\section{Abstract}

Scalp morphea presents as a scarring alopecia in en coup du sabre pattern. We report an unusual presentation of a round hairless patch of morphea on the occipital scalp present for 15 years. The scalp lesion aligned with 2 other hyperpigmented lesions of biopsy-proven morphea in the lower back. Pathology of horizontal sections from the scalp lesion showed follicular dropout, thickening of the collagen bun-

\section{KARGER}

(C) 2017 S. Karger AG, Basel

E-Mail karger@karger.com

www.karger.com/sad dles, and preserved eccrine and follicular structures. Marked lymphocytic perineural infiltrate, a reported clue to the diagnosis of scalp morphea, contributed to the diagnosis. This case is unusual due to its rare clinical presentation. It also highlights the importance of recognizing histopathological clues for the diagnosis of uncommon scalp disorders.

(c) 2017 S. Karger AG, Basel

\section{Introduction}

Morphea is a fibrosing disorder of the skin and the underlying tissues. Classification is based on the clinical presentation and includes circumscribed, linear, generalized, 


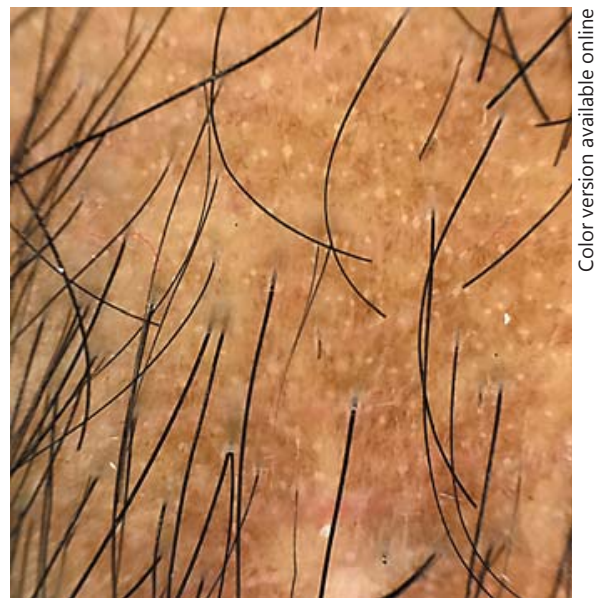

Fig. 1. Trichoscopy showing loss of follicular openings with persistence of pinpoint white dots marking the eccrine sweat ducts. Isolated broken hairs can be observed.

pansclerotic, and mixed variants [1]. The most frequent variant is circumscribed morphea and its more common location is the trunk. The linear variant en coup de sabre (ECDS) is the most frequent subtype in children and it is also the most common clinical variant of scalp morphea $[1,2]$. The rest of the variants is very rare and usually entails bad prognosis. Histologic features of morphea on the scalp have been described on horizontal sections [3]. Collagen bundles are densely packed in the reticular dermis, and eccrine glands appear atrophic $[1,3]$. Presence of columnar epithelial structures was also observed where viable hair follicles were previously located [3].

We present an usual case of long-standing scalp morphea and focus on previously reported histologic clues to the diagnosis.

\section{Case Report}

A 46-year-old man presented with a 15 -year history of a $2-\mathrm{cm}$ well-circumscribed round patch of alopecia on the occipital scalp. The patch was slightly depressed and the overlying skin was atrophic. Trichoscopy showed pinpoint white dots, loss of follicular openings, irregular pigmented network, white linear streaks, and a few broken hairs (Fig. 1). The patient had also 3 other well-demarcated hyperpigmented patches on the back, without palpable induration. The lesion on the occipital scalp and the ones on the posterior back were distributed along the same axial line. The lesions on the back had been diagnosed as morphea consistently on several biopsies obtained through the years.

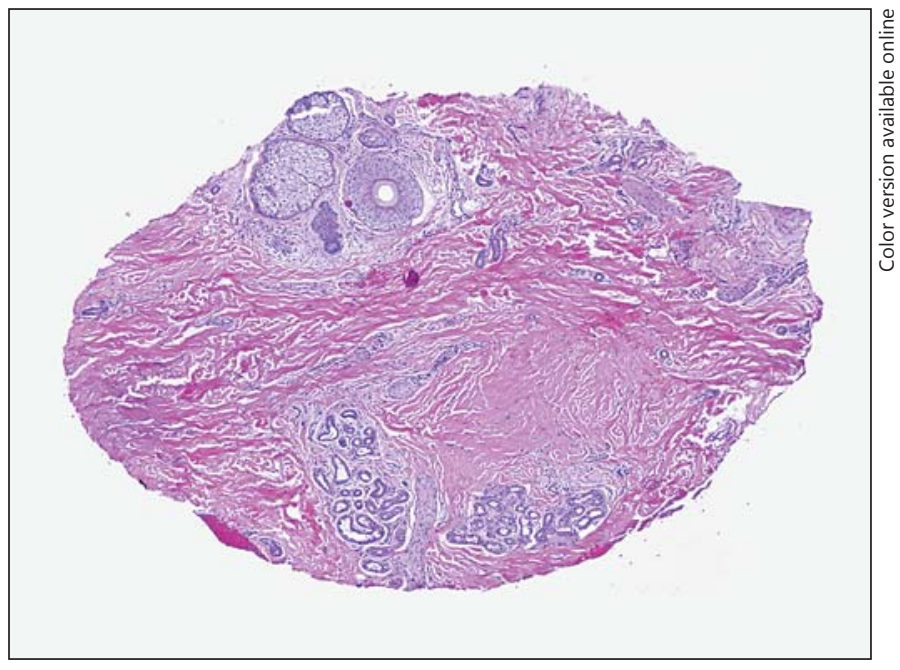

Fig. 2. A transverse section through the level of the isthmus demonstrating an altered follicular architecture with follicular dropout, a terminal anagen follicle, and a telogen follicle with adjacent sebaceous glands. The dermal collagen bundles appear thickened $(\mathrm{H} \& \mathrm{E} . \times 4)$.

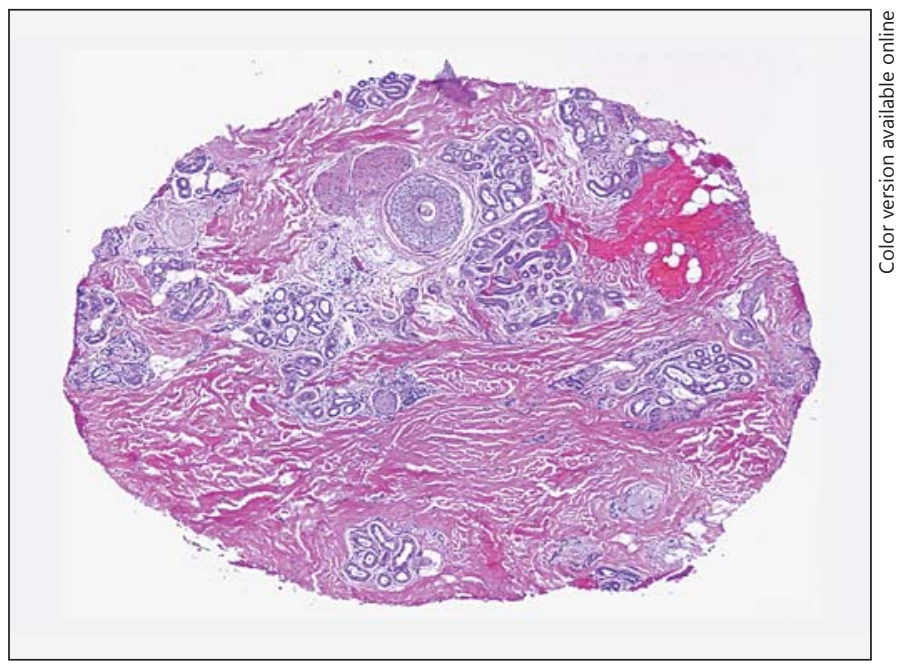

Fig. 3. A transverse section at a low follicular level demonstrating intact eccrine glands and a nerve fiber surrounded by inflammation (H\&E. $\times 4)$.

A 4-mm punch biopsy was obtained from the scalp lesion at a site showing broken hairs on trichoscopy. Hematoxylin-eosin (H\&E) stained horizontal sections revealed decreased follicular density and compact reticular dermis on scanning magnification (Fig. 2). The collagen bundles of the reticular dermis were thickened. The eccrine glands were intact and were situated at the border with the subcutaneous fat (Fig. 3). No atrophic follicular remnants were present. Focal tight perineural lymphocytic inflammation was observed on several sections (Fig. 4). The patient 


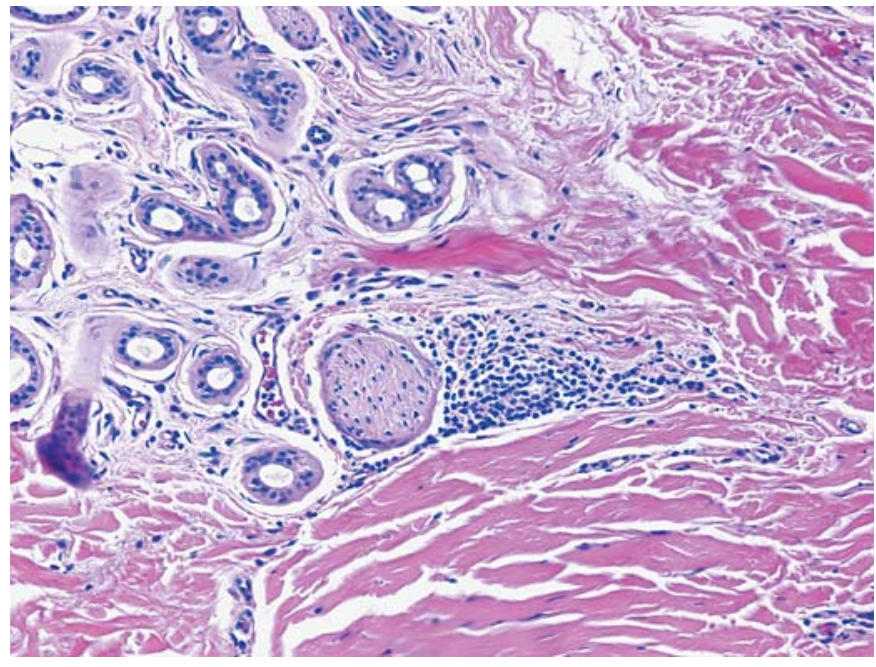

Fig. 4. On high power, the same section reveals a tight marginal perineural infiltrate, consisting of lymphocytes (H\&E. $\times 10)$.

was diagnosed with late-stage burnt-out morphea with secondary alopecia. As clinical signs of activity were absent, no systemic therapy was offered. At the last follow-up, no new lesions were identified.

\section{Discussion}

Our case of scalp morphea is unusual because of the round morphology of the alopecic area on the occipital scalp. Round patches of morphea may present on the vertex, since Blaschko's lines have a spiral distribution that ends on this area [4]. A case of patchy morphea on the scalp has been described [4], but the lesion evolved into linear ECDS over time which had not been observed in our patient over 15 years. Moreover, Blaschko's lines on the occipital area have a linear configuration [5], so a round patch of morphea on this area cannot be linked with morphea ECDS. Our diagnosis for the scalp and posterior trunk lesions was most consistent with burnt-out morphea, which can result in hyperpigmented atrophic patches similar to the superficial variant of atrophoderma of Pasini and Pierini.

Histologically, the earliest stages of morphea show perivascular infiltrate of lymphocytes, plasma cells, and eosinophils in the reticular dermis. Collagen bundles may appear thickened and endothelial cells may be swollen. In the late stages, dense dermal sclerosis with eccrine

Circumscribed Scalp Morphea with

Perineural Lymphocytes on Pathology gland atrophy is the main feature. Most of the adipose tissue is replaced by sclerosis. Sebaceous glands are absent, but erector pili muscles remain $[1,3]$. Remnants of follicles may be observed as columnar and epithelial structures resembling telogen follicles/telogen germinal units [3]. Our case did not reveal the atrophic adnexal features of linear morphea. Lymphocytic perineural infiltrate suggested the diagnosis, a sign that was previously described in biopsies from morphea $[6,7]$. Perineural inflammation in skin lesions of morphea can be identified in $57.5 \%$ of cases and this frequency increases to $84 \%$ when specific immunohistochemical stains are used [7]. This sign can be found in all types of morphea; however, it is more common in inflammatory stages than in burned out stages of morphea. The most frequent pattern is concentric perineural inflammation [7]. Lymphocytic perineural infiltrate can also be observed in infections (classically related to tuberculoid leprosy, but also to syphilis and herpetic infections) and in inflammatory disorders such as sarcoidosis, Behçet disease, and eosinophilia-myalgia syndrome $[8,9]$. In morphea, perineural inflammation tends to be intense and concentric to the nerves [7].

To our knowledge, there are no cases of circumscribed round morphea involving the scalp reported so far. Thereby a high clinical suspicion is needed for an accurate diagnosis. Tight lymphocytic perineural infiltrate is a helpful histopathologic feature in the diagnosis of secondary alopecia due to morphea.

\section{Statement of Ethics}

Verbal photographic and informed consent was obtained from the patient described in this article. The study protocol has been approved by the institute's committee on human research.

\section{Disclosure Statement}

The authors declare that they have no conflicts of interest regarding this study. This article has no funding source.

Skin Appendage Disord 2017;3:175-178

DOI: $10.1159 / 000471855$ 


\section{References}

1 Fett N, Werth VP: Update on morphea: part I. Epidemiology, clinical presentation, and pathogenesis. J Am Acad Dermatol 2011;64: 217-228.

2 Mazori DR, Wright NA, Patel M, Liu SW, Ramachandran SM, Franks AG, Vleugels RA, Femia, AN: Characteristics and treatment of adult-onset linear morphea: a retrospective cohort study of 61 patients at 3 tertiary care centers. J Am Acad Dermatol 2016;74:577579 .
3 Pierre-Louis M, Sperling LC, Wilke MS, Hordinsky MK: Distinctive histopathologic findings in linear morphea (en coup de sabre) alopecia. J Cutan Pathol 2013;40:580-584.

4 Asano Y, Ihn H, Tamaki K: An unusual manifestation of linear scleroderma ,en coup de sabre" on the vertex and frontoparietal regions. Clin Exp Dermatol 2007;32:758-759.

5 Happle R, Assim A: The lines of Blaschko on the head and neck. J Am Acad Dermatol 2001; 44:612-615.

6 Goh C, Biswas A, Goldberg LJ: Alopecia with perineural lymphocytes: a clue to linear scleroderma en coup de sabre. J Cutan Pathol 2012;39:518-520.
7 Dhaliwal CA, Mackenzie AI, Biswas A: Perineural inflammation in morphea (localized scleroderma): systematic characterization of a poorly recognized but potentially useful histopathological feature. J Cutan Pathol 2014; 41:28-35.

8 Abbas O, Bhawan J: Cutaneous perineural inflammation: a review. J Cutan Pathol 2010;37: 1200-1211.

9 Subtil A, LeBoit PE: Lymphocytes + nerves = ? Am J Dermatopathol 2000;22:362-364. 